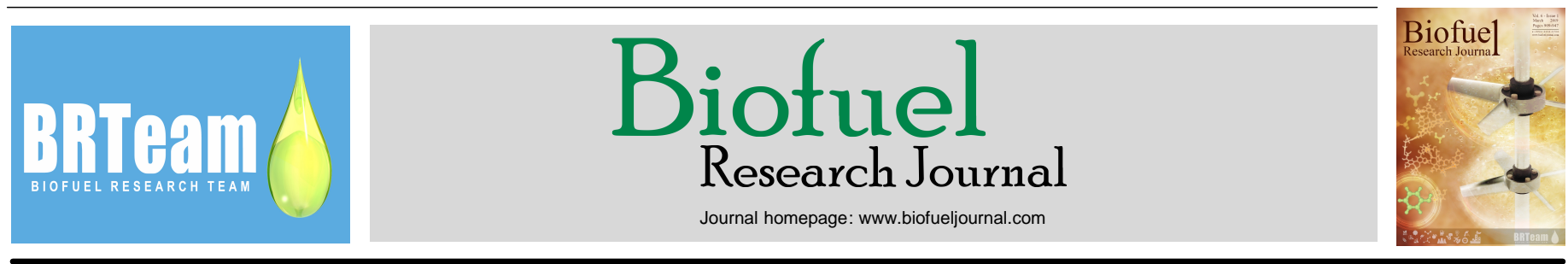

Original Research Paper

\title{
Effect of oxy-fuel combustion on ash deposition of pulverized wood pellets
}

\author{
Khalidah Al-Qayim ${ }^{1,2, *}$, William Nimmo ${ }^{1}$, Mohammed Pourkashanian ${ }^{1}$
}

${ }^{I}$ Energy 2050 Group, Department of Mechanical Engineering, Faculty of Engineering, University of Sheffield, Sheffield, S10 2TN, UK.

${ }^{2}$ Oil \& Gas Refinery Engineering Dept, Al-Farabi University College, Aldorrah-masafi Street, Baghdad, Iraq.

\section{HIGHLIGHTS}

$>$ Deposition tendencies of wood pellets are predicted by the ash stream compositions.

$>$ Wood pellets have a low tendency for slagging and high tendency for fouling.

$>$ Oxy-fuel combustion reduces slagging yet increases fouling tendencies of alkali sulphates.

$>$ Oxy-fuel combustion can reduce the propensity of high-temperature corrosion problems.

$>$ Ash behaviour of wood pellets is significantly changed when replacing air-fuel with oxy-fuel conditions.

\section{GRAPHICAL ABSTRACT}

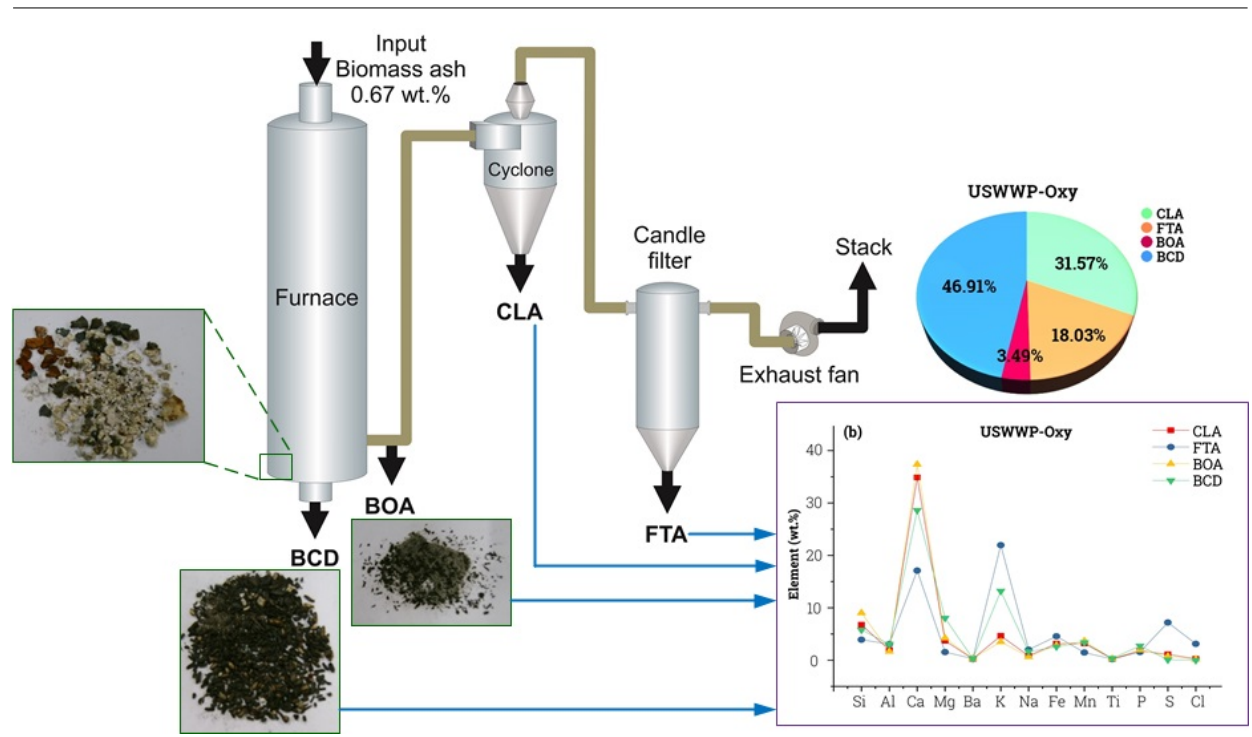

\section{ARTICLE INFO}

\section{Article history:}

Received 4 October 2018

Received in revised form 11 January 2019

Accepted 12 January 2019

Available online 1 March 2019

\section{Keywords:}

Wood pellets

Oxy-fuel

Alkali

Slagging

Fouling

FactSage

\begin{abstract}
Biomass is a clean alternative fuel to coal in terms of carbon, $\mathrm{NO}_{\mathrm{x}}$, and $\mathrm{SO}_{2}$ emissions in the power generation sector. However, ash deposition problems have been a concern with biomass fuels due to the high alkali and residual sulphur contents in the ash forming particles. In this study, the influence of oxy-fuel firing conditions of wood pellets combustion on ash partitioning and deposit formation, were investigated experimentally on a $250-\mathrm{kW}$ pilot scale pulverized furnace and theoretically through chemical equilibrium modelling using the FactSage program. Oxy-fuel combustion case was compared with air-fuel case in this assessment. The results of this study showed that wood pellets had a low tendency for radiation zone slagging, but, had a high fouling tendency in the convective passes. It is possible that oxy-fuel combustion inhibited the release of volatile elements to the gas phase in the initial stages of the combustion, thus reducing the alkali sulphates slagging, increasing however, the alkali sulphate fouling tendencies on the convective passes. Moreover, the effect of the oxy-fuel environment on the ash formation was significant. The chemical equilibrium modelling showed reasonable predictions of the ash behaviour of wood pellets in terms of alkali behaviour and explained to some extent the influence of the oxy environment on ash deposit formation.
\end{abstract}

(c) 2019 BRTeam. All rights reserved.

* Corresponding author at: Tel.: 009647705061458

E-mail address: khalidah.alqayim@alfarabiuc.edu.iq

Please cite this article as: Al-Qayim K., Nimmo W., Pourkashanian M. Effect of oxy-fuel combustion on ash deposition of pulverized wood pellets. Biofuel Research Journal 21 (2019) 927-936. DOI: 10.18331/BRJ2019.6.1.4 


\section{Introduction}

Ash deposition is a classic problem in solid fuel combustion power plants. Biomass ash depositions can cause heat transfer deficiency and corrosion problems to the boiler tubes. The release of inorganic elements from a fuel particle during combustion is driven by their volatility and the chemical reactions of organic components in the fuel (Jenkins et al., 1998). At combustion temperatures, the most notably volatile materials are compounds of alkali, chlorine, sulphur, and phosphorous (Pronobis, 2005; Vamvuka et al., 2008; Sommersacher et al., 2012). Elements such as silicon, alkali, sulphur, and alkaline earth metals react to form elemental or poly-silicates that melt at a temperature lower than $1100{ }^{\circ} \mathrm{C}$ or form alkali sulphates that can condense on the heat transfer surfaces in the combustor leading to unavoidable deposition on the furnace walls or boiler tube surfaces, namely slagging and fouling, and less bothersome soot (Miles et al., 1996).

Slagging is the fused glassy deposits on the fireside walls of the furnace in the radiation zone that are formed from the reaction of the fuel ash silica with alkali oxides, hydroxides, and aluminium oxide to form low-melting temperature silicates at less than $800{ }^{\circ} \mathrm{C}$ (Shao et al., 2012). Fouling is the condensation of the volatile alkali sulphates, chlorides, and carbonates either on the ash particles forming sticky ash agglomerates on the convection walls, or on the boiler tubes that are parallel to the gas flow, i.e. the convective passes. On the other hand, the release of the fuel sulphur and chlorine can cause severe corrosion problems on the boiler tube surfaces in the presence of water vapour and alkali hydroxides in the flue gas (FG) (Baxter et al., 1998). Historically, corrosion was found under the fouling layers on the heat exchanger tubes of the power station boilers. Miles et al. (1996) found that with the higher alkali, silica, chlorine or sulphur content in the biomass fuel, the high temperature of exit flue gas promotes slagging and deposition on the boiler surfaces. The presence of chlorine also assists in the transfer of alkali metals from the fuel to the furnace surfaces as chlorides. Gruber et al. (2015) measured the high temperature corrosion rate of various types of wood combustion in a $50 \mathrm{~kW}$ grate furnace, and correlated this rate exponentially with the FG temperature and linearly with FG velocity and the boiler steel pipes temperature. However, with the pulverized fuel combustion, caution must be applied due to the difference in the fuel particle size, fuel transport with the primary air, and the full process design.

So far, a considerable amount of literature has been published on wood ash deposition (Baxter, 1993; Ragland et al., 1995; Wei et al., 2005; Nutalapati et al., 2007), however, there is little published data on the ash deposition behaviour of the wood pellets under air combustion and oxy-fuel combustion (Ohman et al., 2004; Wiinika et al., 2007; Houshfar et al., 2014). One of the studies on wood pellets combustion was presented by Ohman et al. (2004) who tested six types of softwood sawdust and bark pellets in three $10-15 \mathrm{~kW}$ burners. They found that the bark had the highest slagging tendency, and the maximum combustion temperature at which slagging occurs was found to be $1100{ }^{\circ} \mathrm{C}$. They compared the mineral oxides in the fly ash and the slag on the burner, and found that all fuel slags mainly consisted of $\mathrm{Si}, \mathrm{K}, \mathrm{Ca}$ and $\mathrm{Al}$, and the slagging tendency increased with the increase of ash content in the fuel. In addition, they found that the critical slagging temperature decreases with the increase of ash content in the fuel. This can be attributed to the preference of alkali silicates occurrence over the alkali sulphates due to the high content of silica in the fuel.

Another work performed by Wiinikka et al. (2007) where an $8 \mathrm{~kW}$ fixed bed reactor was used to burn three types of wood pellets, examined the high temperature emissions in the flue gases. Their results have shown a high dependency of aerosol formation in the flue gases on the fuel ash composition and the combustion temperature. Shao et al. (2010) co-fired wood pellets with coal to investigate the deposition rate and found that $50 \%$ co-firing produces the lowest deposition rate. In addition, they reported that the higher moisture content in the fuel, the lower deposition rate occurs. Fryda et al. (2009) is one of the few research works on oxy-biomass combustion, though on a bench scale. They found that oxy-fuel environment increases ash deposition during coal/biomass blends combustion.

In this work, therefore, a pilot scale study on the effect of the oxy-fuel environment on the fuel ash distribution pattern and the deposition formation of white wood pellets are investigated. A comparison between biomass and coal ash behaviors is also performed to assess the influence of fuel ash composition on the ash partitioning and deposition incidence.

\section{Materials and Methods}

\subsection{Fuel characterization}

Biomass sample used in this work was the US milled wood pellets (USWWP) with $95 \%$ of particles at a size less than $500 \mu \mathrm{m}$, imported to the UK by a power company in 2015. Figure 1 shows samples of the USWWP before and after milling.

Wood pellets were examined for proximate and ultimate analysis. The characterization methods used in this study were based on the European and British Standard for Solid Biofuel Specifications and Classes. A Carbolite muffle furnace SCF 1100 and Carbolite LHT6/30 forced-air convection oven were employed to perform the proximate analysis tests. In addition, a Thermo Flash 2000 Element Analyzer was used to test the C, H, N, and S content of the fuel samples and the produced ashes from the combustion tests. Moreover, the gross calorific values (GCV) were measured by a Parr 6200 bomb calorimeter. The proximate and ultimate analysis results are listed in Table 1.
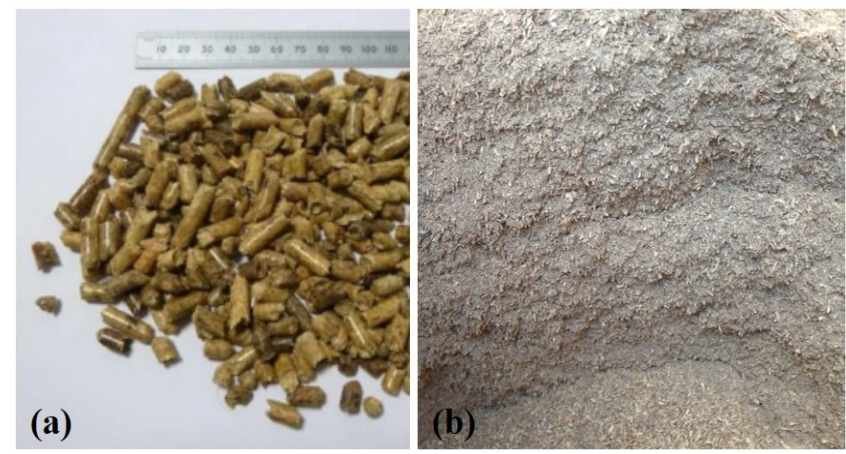

Fig. 1. Samples of the USWWP; (a) before milling and (b) after milling.

\subsection{Combustion rig description}

The pulverized combustion testing rig consisted of a $250 \mathrm{~kW}$ down fired cylindrical furnace using a burner that was designed particularly to fire pulverised biomass as well as firing coal under either air or $\mathrm{O}_{2} / \mathrm{CO}_{2}$ mixtures namely oxy-fuel firing. The furnace was $4 \mathrm{~m}$ long, made of eight $500 \mathrm{~mm}$ long sections, with 900/1100 $\mathrm{mm}$ inner/outer diameters. The

Table 1.

Proximate and ultimate analysis of the fuel used in this study.

\begin{tabular}{|c|c|c|c|c|c|c|c|c|c|c|c|}
\hline \multirow[b]{2}{*}{ Sample } & \multicolumn{3}{|c|}{ Proximate Analysis (Wt.\%, db ${ }^{\mathbf{a}}$ ) } & \multirow{2}{*}{$\mathrm{GCV}^{*}(\mathbf{k J} / \mathbf{k g}, \mathbf{d b})$} & \multirow{2}{*}{$\mathrm{NCV}^{* *}(\mathrm{~kJ} / \mathbf{k g}, \mathrm{db})$} & \multicolumn{6}{|c|}{ Ultimate analysis (wt. \%, daf' $)$} \\
\hline & Ash & VM & FC $^{\mathbf{b}}$ & & & $\mathbf{N}$ & $\mathrm{C}$ & $\mathbf{H}$ & $\mathbf{S}$ & $\mathbf{O}^{\mathbf{b}}$ & $\mathbf{C l}$ \\
\hline USWWP & 0.70 & 91.33 & 7.97 & 19661 & 18335 & 0.18 & 49.34 & 6.14 & $<0.1$ & 44.34 & $<0.01$ \\
\hline
\end{tabular}




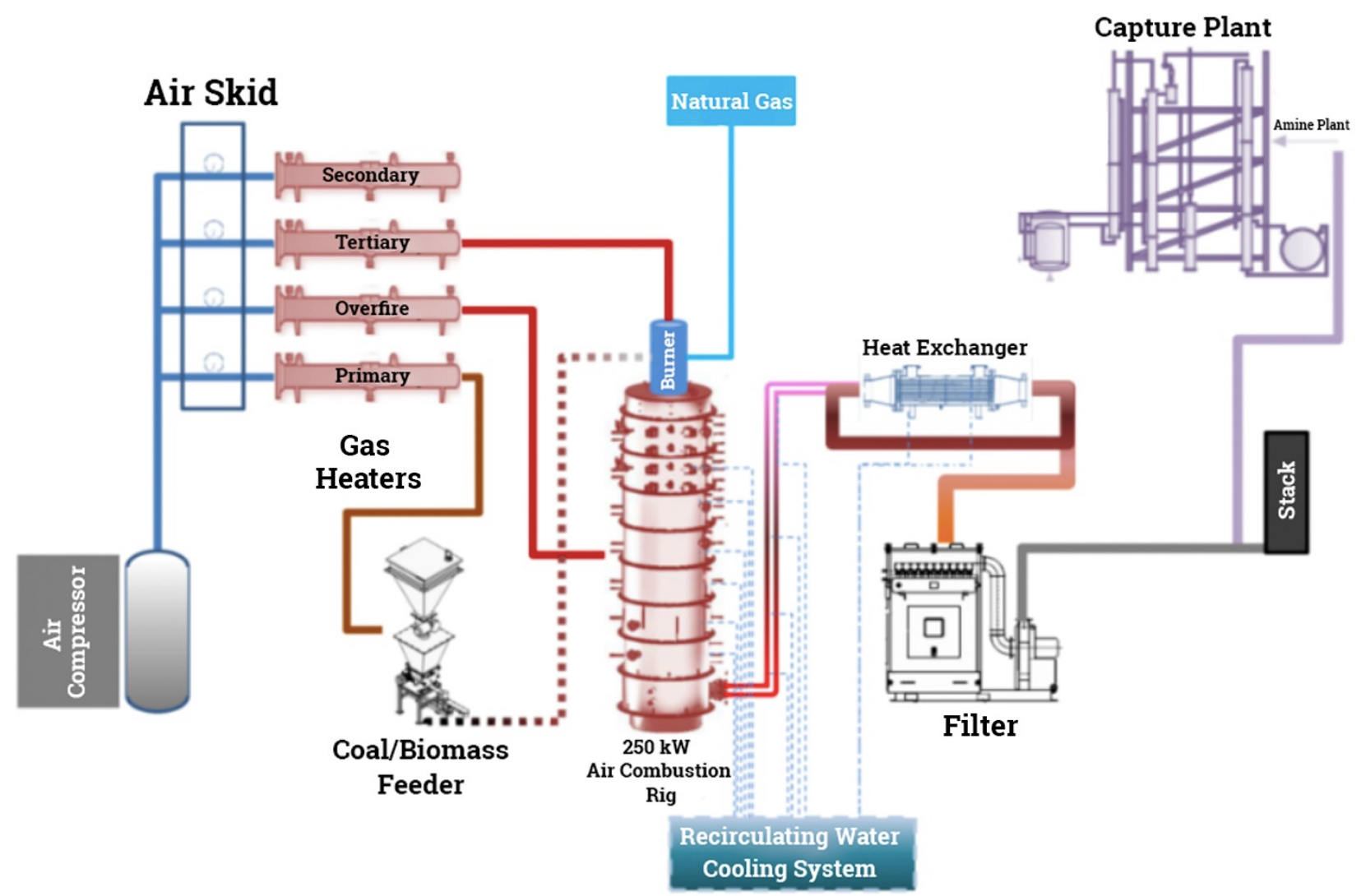

Fig. 2. A schematic diagram of the $250-\mathrm{kW}$ biomass combustion testing rig.

refractory was made of $100 \mathrm{~mm}$ thick, lightweight alumina silicate that led to a more rapidly heated furnace than a furnace lined with refractory bricks. The unit had a dedicated biomass feeder with a maximum capacity of $80 \mathrm{~kg}^{-1} \mathrm{~h}^{-1}$, supplied with a dedicated air and $\mathrm{O}_{2} / \mathrm{CO}_{2}$ metering skid. The flue gas exhaust left the bottom of the furnace to a cyclone to remove the large particulates of the fly ash. The flue gas was then cooled to a temperature of about $800{ }^{\circ} \mathrm{C}$, and then it passed through a hot temperature candle filter to remove the remaining fly ash. A schematic diagram of the pilot scale rig is illustrated in Figure 2.

\subsection{Experimental design}

Two combustion baseline cases were included in this investigation: air-fuel and oxy-fuel cases. Each baseline case was achieved by optimizing the burner performance with fuel-oxidant flowrates, in-flame temperatures, and the exit oxygen and gas emissions.

The thermal input of the two combustion cases were set at $200 \mathrm{~kW}$, and the oxy-fuel case oxidant was enriched with $27 \%$ by volume oxygen. This ratio was chosen to achieve a similar molar percent to the one of oxygen in the air, i.e., $21.2 \%$. The fuel and oxidant flowrates were adjusted to maintain $3.5-4.3 \%$ exit oxygen (dry basis). Table 2 shows the experimental matrix of the operational parameters for the two case studies.

\subsection{Ash sampling}

During the testing day, samples of the fly and bottom ashes were collected after reaching a steady state condition in the biomass feeding rate, air flowrate, and gaseous emission values. Normally, a steady state was achieved after 30$40 \mathrm{~min}$ of continuous running. This period was found necessary to reach the maximum adiabatic temperature in the flame zone, and the required exit oxygen concentration. This observation applies to all pervious experimental work on this specific rig. When steady state was reached, stable data readings were deemed to occur for at least $30 \mathrm{~min}$, then, readings were recorded and ash
Table 2.

Experimental matrix of the $250 \mathrm{~kW}$ pulverized combustion rig.

\begin{tabular}{llll}
\hline Parameter & Unit & USWWP-air & USWWP-oxy \\
\hline Thermal input & $\mathrm{kW}$ & 200 & 200 \\
Fuel flowrate & $\mathrm{kg} \cdot \mathrm{h}^{-1}$ & 41.86 & 41.86 \\
Total oxidant : fuel ratio, $\lambda$ & ratio & 1.22 & 1.18 \\
Total oxidant flowrate & $\mathrm{L} \cdot \mathrm{min}^{-1}$ & 3898 & 2460 \\
Total oxygen in Oxy case & $\mathrm{kg} \cdot \mathrm{h}^{-1}$ & & 61 \\
Primary\% of total air & $\%$ vol. & 18.0 & - \\
Oxygen ratio in oxy-fuel & $\%$ vol. & & 27 \\
Exit $\mathrm{O}_{2 \text { (dry) }}$ & $\%$ vol. & 3.57 & 3.6 \\
TPA & $\mathrm{K}$ & 294.8 & 291.8 \\
$\mathrm{~T}_{\mathrm{TA}}$ at burner inlet & $\mathrm{K}$ & 250 & 250 \\
\hline
\end{tabular}

samples were taken. As shown in Figure 3, the fly ash was collected from three different points; the cyclone ash (CLA) that was collected in a removable catch pot connected to the bottom of the cyclone and the bottom ash (BOA) that was collected at the flue gas exit pipe from the bottom section of the furnace. Sample collection took place for periods of $1 \mathrm{~h}$ giving a sample weight of 70-150 g of the cyclone ash and $20 \mathrm{~g}$ of the bottom ash. Another fly ash sample was collected from the candle filter ash (FTA) at the end of the testing day which represented the aerosol particulates in the fly ash. Due to the difficulty to extract samples from the filter at different operating conditions during the test run, the FTA sample 
represented the total ash accumulated during the testing day, and an average hourly flowrate was taken for the mass balance calculations.

In addition, the biomass had another source of ash during combustion that was the large particles of unburned fuel and char residue, dropped from the flue gas to the water tray combined with ash depositions that were formed on the furnace walls and base, named here as the bottom char and deposition (BCD). Ash samples were preserved in sealed containers and flushed with nitrogen for further analysis to determine the carbon-in-ash and ash mineral composition. Each analysis test was repeated three times to ensure measurement accuracy and repeatability.

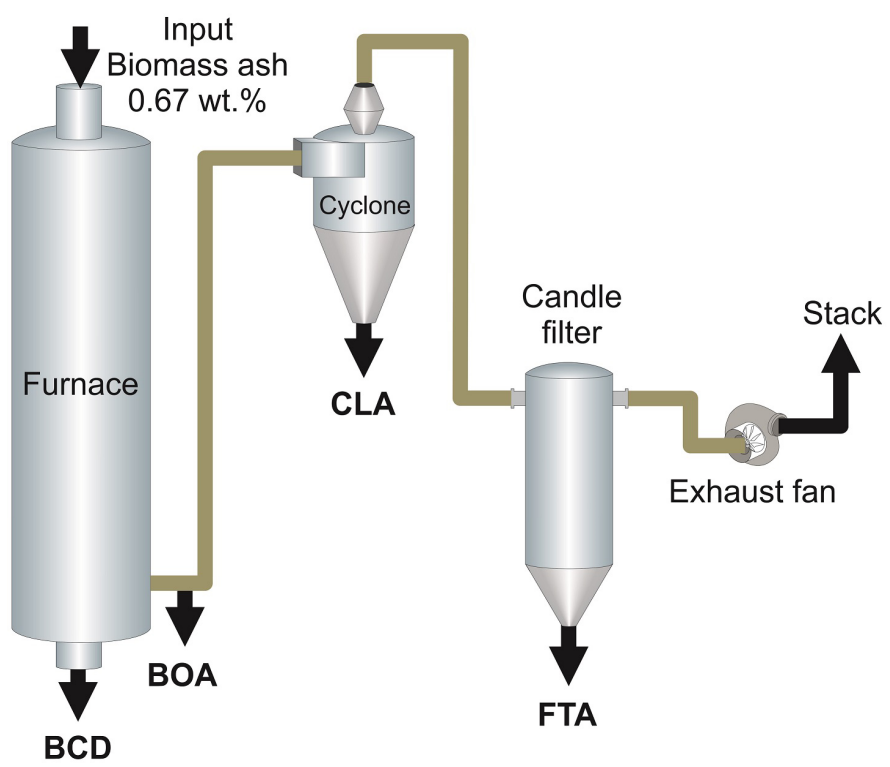

Fig. 3. Illustration of the ash collection points in the combustion rig.

\subsection{X-Ray fluorescence analysis}

Compositional analysis of the USWWP ash that was produced at a temperature of $550^{\circ} \mathrm{C}$, and the collected ash samples of CLA, FTA, BOA, and $\mathrm{BCD}$ were carried out to characterize the ash mineral partitioning in comparison with the initial fuel ash composition. The analysis was performed by the X-ray fluorescence (XRF) method and the PANalytical Zetium (XRF) was employed for this purpose. The machine uses a rhodium anode to produce the electron beam and the energy dispersive X-ray (EDX) was applied to detect the elements from sodium to uranium. Ash samples were placed in $37 \mathrm{~mm}$ open cups that were sealed in the bottom with a levelled Mylar film, making sure that the sample amount was enough to fully cover the base. Each sample test was repeated twice to ensure measurement accuracy and repeatability.

\subsection{Estimation of errors}

Data were gathered from multiple sources at various time points during the experimental work in this study, leading to several sources of error. The main error sources identified in this study were instrumental and experimental errors. The main equipment used for the measurements in the experimental work were gas analyser, thermocouples, biomass feeder, air rotameters, analytical equipment used for fuel and ash compositional analysis, and fuel burnout (furnaces, TGA, balance, elemental analyser, Bomb calorimeter, and XRF).

Error values were collected from the analyser and equipment manuals, or factory calibration certificates. The gas analyser accuracy and repeatability was $\pm 1 \% \mathrm{O}_{2}, \mathrm{NO}, \mathrm{CO}_{2}, \mathrm{CO}$, and $\mathrm{SO}_{2}$. The temperature errors associated with the thermocouple measurements were determined by the manufacturer as $\pm 3 \%$. Similarly, the air rotameters had a $\pm 2 \%$ error. The actual biomass feeding rate was fluctuating around the set point by less than $1 \%$ due to the vibration of the platform or due to the change in the ingress pressure. The list of instrumental errors in the flowrates, gas composition, and fuel analysis is shown in Table 3.

Table 3.

Instrumental errors during data measurement.

\begin{tabular}{llc}
\hline Instrument & Source of Error & Error value \\
\hline 250 $\mathbf{k W}$ rig experiments & & \\
Thermocouples & Measurement accuracy & $\pm 3 \%$ \\
Biomass feeder & screw drive variation & $\leq \pm 1 \%$ \\
Drift - Biomass feeder & Feeder adjustment & $5 \mathrm{sec}$ \\
Air rotameters & Measurement accuracy & $\pm 2 \%$ \\
Gas analyzer & Measurement accuracy & $\pm 1 \%$ \\
T: Zero- Gas analyzer & Measurement accuracy & $\pm 0.03 \%$ \\
T: Span- Gas analyzer & Measurement accuracy & $\pm 0.1 \%$ \\
Drift -Gas analyzer & Measurement accuracy & $1 \%$ per $1 \mathrm{~h}$ \\
Analytical equipment & & \\
Carbolite oven & Temp measurement variance & $\pm 4 \mathrm{~K}$ \\
Carbolite muffle furnace & Temp measurement variance & $\pm 5 \mathrm{~K}$ \\
CHN/S analyzer & Measurement accuracy & $\pm 0.1 \%$ \\
Bomb calorimeter & Mass measurement, acid heat factor & $\pm 0.1 \%$ \\
Analytical balance & Balance measurement accuracy & $\pm 0.1 \mathrm{mg}$ \\
TGA & $\begin{array}{l}\text { Sample and Program Temperature } \\
\text { difference }\end{array}$ & $\pm 5 \mathrm{~K}$ \\
\hline & & \\
\hline
\end{tabular}

The main experimental sources of error were during the ash sample collection. Although it was possible to collect CLA and BOA samples accurately with time, the FTA sample represented the average of the total testing day operation. Knowing that there were fluctuations in the fuel and oxidant flowrates during the testing day, and ultimately the temperature and the gaseous emissions change, this could produce some errors in the composition and amount of the collected ash. Another source of error was the ingress in the primary air that was sometimes hard to control and maintain constant. Its vacuum pressure usually fluctuated between $-9 \mathrm{psi}$ to $+5 \mathrm{psi}$, and that could influence the biomass feeding rate.

\subsection{Control measures for errors}

The gaseous emissions were measured directly as volume fractions, either ppm or $\%$ of the flue gas, and therefore, the volumetric changes due to the pressure and temperature were avoided. Furthermore, the gas analyser calibration data of the zero and span conditions were used to correct the gaseous data for instrumental uncertainties. For the ingress in the primary line, the biomass feeder was self-controlled for variations in the pressure inside the balance chamber and drop tube. In addition, a continuous monitoring of the ingress pressure not to exceed \pm 1 bar was sustained.

All the compositional analysis results were the mean value of triplicates to ensure repeatability. The TGA and CHN/S analysers were calibrated daily before the testing runs. The standard deviation (STDEV) values were calculated and when there was a high deviation in the mean value, the analysis was repeated more times. The STDEV values were presented with the data results.

\subsection{Chemical equilibrium modelling}

To support the experimental findings during the combustion process, chemical equilibrium model calculations were performed using the software program FACTSage 7.0 with thermodynamic data taken from the FACT and SGTE databases (Bale et al., 2015). The program uses the method of minimization of the total Gibb's free energy of the system. Two steps of calculations were performed to predict the ash forming elements 
behaviour. The first step was the formation of mineral compounds with sulphur and chlorine in the flame zone at a maximum temperature $1500{ }^{\circ} \mathrm{C}$ for the airfuel case and $1400{ }^{\circ} \mathrm{C}$ for the oxy-fuel case. The databases used in the calculations were FT oxide-SLAGB-liq with $\mathrm{SO}_{4}$ and FT salt-AOH in addition to other possible salt solutions at low and high temperatures. In the second step, the chemical equilibrium condensation behaviour of the ash particle forming material during subsequent cooling of the flue gases from $1400-1500{ }^{\circ} \mathrm{C}$ to 200 ${ }^{\circ} \mathrm{C}$ was modelled to predict the slagging degree of the species formed in the first step. A fully oxidizing condition was assumed with experimental stoichiometric air-to-fuel ratios of 1.18-1.20 under atmospheric pressure.

\section{Results and Discussion}

\subsection{Fuel ash composition}

Elemental composition analysis of USWWP ashes was performed with the XRF method and the results are given in Table 4. From the data presented in Table 4, it can be observed that the USWWP ash had significantly high contents of calcium and potassium while on the other hand; it had low contents of silica and alumina. Potassium is the foremost source of alkali in wood pellets (Miles et al., 1996; Jenkinz et al., 1998; Nutalapati et al., 2007). Therefore, it can be expected that the biomass can cause high fouling and corrosion problems in the boiler tubes, and low slagging problems in the radiation sections of the furnace. However, there are various possibilities of chemical reactions in the multi-element composition, not only depending on the fuel composition but on the combustion temperature as well (Miles et al., 1996; Wiinika et al., 2007). Chemical equilibrium at the combustion temperature can steer the reaction preference towards a certain product rather than another for the same elements.

Table 4.

Ash composition of the USWWP, via XRF analysis.

\begin{tabular}{lll}
\hline Element & USWWP & STDEV \\
\hline $\mathrm{Si}$ & 5.87 & \pm 0.08 \\
$\mathrm{Al}$ & 2.67 & \pm 0.03 \\
$\mathrm{Ca}$ & 28.82 & \pm 0.01 \\
$\mathrm{Mg}$ & 5.38 & \pm 0.01 \\
$\mathrm{Ba}$ & 0.29 & \pm 0.01 \\
$\mathbf{K}$ & 11.74 & \pm 0.01 \\
$\mathrm{Na}$ & 1.41 & \pm 0.02 \\
$\mathbf{F e}$ & 3.14 & \pm 0.09 \\
$\mathrm{Mn}$ & 2.98 & \pm 0.04 \\
$\mathrm{Ti}$ & 0.29 & \pm 0.00 \\
$\mathbf{P}$ & 2.19 & \pm 0.01 \\
$\mathbf{S}$ & 1.72 & \pm 0.01 \\
$\mathrm{Cl}$ & 0.27 & \pm 0.01 \\
\hline
\end{tabular}

\subsection{Distribution of ash streams}

Ash stream flowrates were estimated from the samples collected at the furnace exit FG, BOA, the CLA, and the FTA. In addition, the unburned fuel/char particles and the deposited ash particles in the water tray (BCD) at the bottom of the furnace were also collected at the end of the testing day, as this comprises a considerable fraction of the unburned fuel. Traditionally, this residue is the main source of thermal losses in biomass combustion due to its high carbon content.

Figure 4 displays photographs of the BOA, BCD char, and the deposition particles collected from both USWWP-air (left) and USWWP-oxy (right) cases. From the photographs in Figures $4 a-d$, it can be seen that the char particles in the air combustion case were lower quantity and finer than the ones in the oxy combustion case, indicating better combustion and higher burnout in
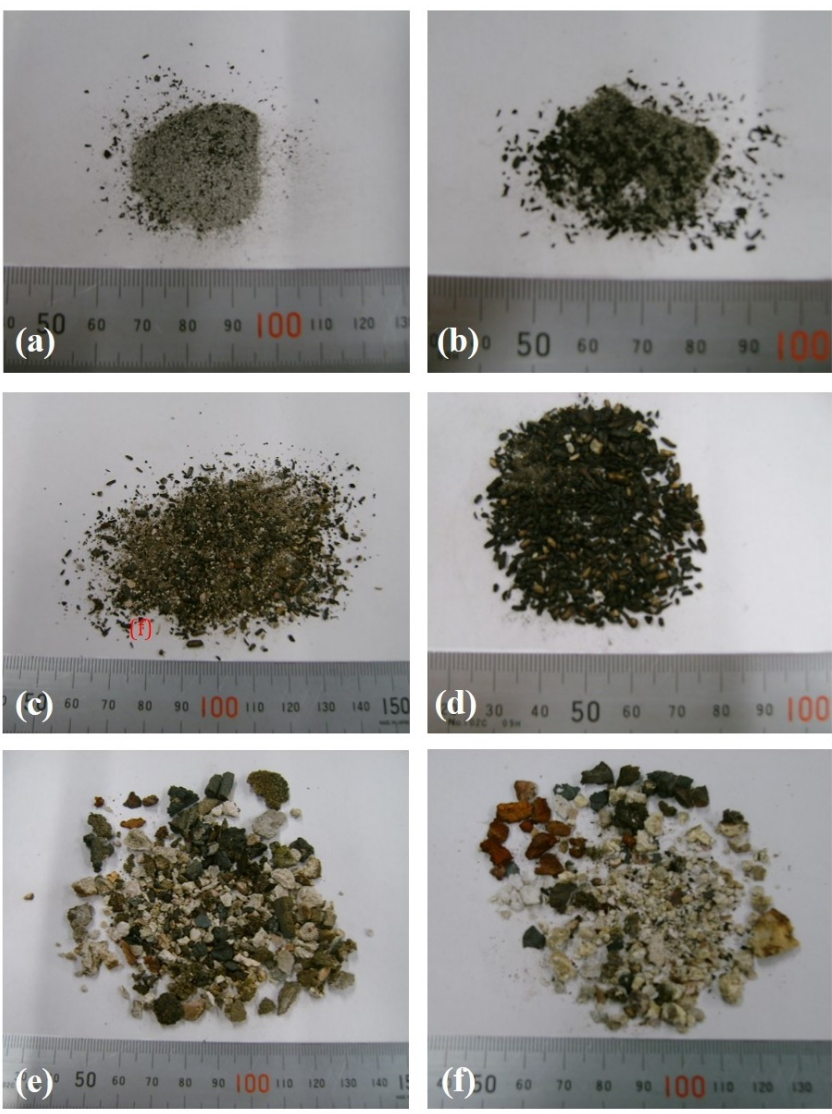

Fig. 4. Photographs of the biomass combustion ashes in air-biomass (left) and oxy-biomas (right) cases; (a) and (b): BOA; (c) and (d): BCD char; (e) and (f): bottom depositions.

the former than the latter case. The reason for this can be explained by the difference in the residence time of the biomass particles in the furnace. The total air flowrate in the air-biomass case is higher than the oxy-fuel case therefore; larger particles can drop down to the furnace bottom due to the lower flowrate. In both cases of combustion, refractory particles and large deposition agglomerates were found. From the photographs in Figures $4 \mathrm{e}$ and $\mathbf{f}$, we can see that the deposition particles combine with several types of deposits as well as considerable amounts of the refractory deposition. These were observed to vary in hardness, colour, and structure.

To illustrate the ash distribution pattern, the mass in parts per million (ppm) of pure CLA, FTA, and BOA, were normalized to the original fuel ash content. This method served to calculate the total undetected ash parts (i.e., BCD) that was anticipated mainly as bottom depositions on the furnace walls and base, and insignificant amounts of submicron aerosols that could be transported with the flue gases.

Figure 5 compares the fractional distribution of the fuel ash on the four ash streams in two combustion cases. Interestingly, the biomass-air had lower CLA, FTA, and BOA, though, higher BCD than the oxy combustion had, suggesting a different path of chemical reactions in the two combustion cases, meaning that the oxy-fuel environment reduced the ash deposition occurrence of wood pellets. This result was not in agreement with the conclusion drawn by Fryda et al. (2009). The disagreement between the two results can be ascribed to many reasons; first, the difference in fuel mix, as they used blends of coal and biomass whereas pure biomass was used in this study. Second, the bench scale test does not simulate boiler conditions, where alkali rapidly volatile and subsequently condense on the furnace walls or fly ash, which reduces deposition at the bottom of the furnace. Thirdly, swirl mixing and heat losses in the pilot scale during combustion may also affect the deposition occurrence. 


\section{USWWP-Air}

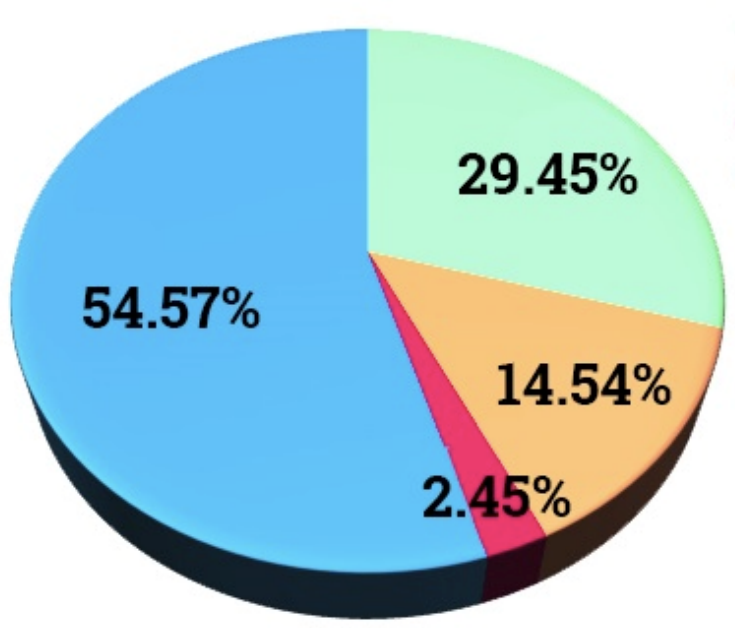

CLA

FTA

BOA

BCD

\section{USWWP-Oxy}

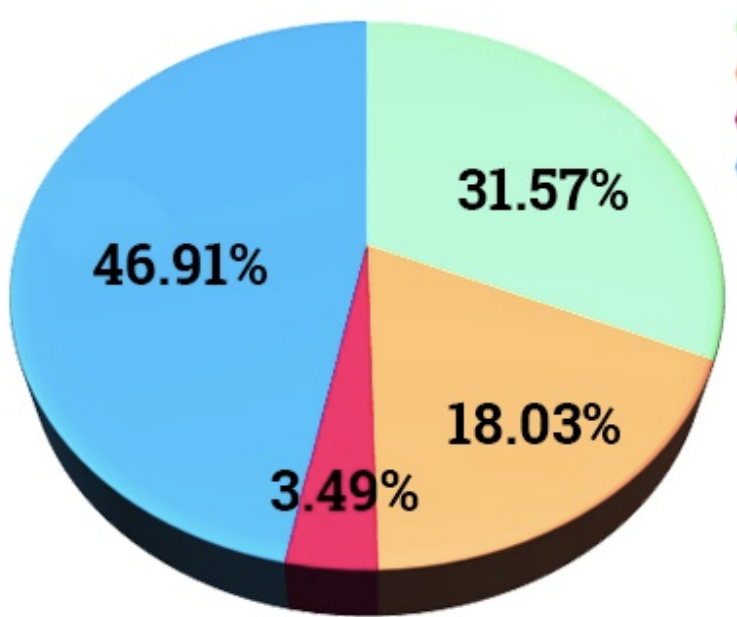

CLA

FTA

BOA

BCD

Fig. 5. Ash fractional distribution as percentage of CLA, FTA, BOA, BCD in two combustion cases USWWP-air, and USWWP-oxy.

\subsection{Ash compositional analysis}

Further investigation on the ash distribution was performed using the data collected from the XRF analysis of the different ash streams. All ash samples from the rig, were collected immediately during the test in sealed containers then flushed with nitrogen to keep dry until further analysis. Each ash sample was analyzed for the elemental composition $(\mathrm{Si}, \mathrm{Al}, \mathrm{Ca}, \mathrm{Mg}, \mathrm{Ba}, \mathrm{K}, \mathrm{Na}, \mathrm{Fe}$, $\mathrm{Mn}, \mathrm{Ti}, \mathrm{P}, \mathrm{S}$, and $\mathrm{Cl}$ ). The XRF analyses showed absolute errors in the readings ranging between $0.01 \%$ for $\mathrm{Ti}$ and $0.20 \%$ for $\mathrm{Ca}$, the other elements falling in this range. The repeatability of each test was in the range of $0.00-1.60$ standard deviation in the mean of duplicate readings. The highest errors were in the $\mathrm{Ca}$ measurement. To estimate the BCD composition, mass balance of each element in the fuel ash and the produced ash streams was performed. The analysis results are presented in Table 5 and mapped in Figure $\mathbf{6}$ for the USWWP-air and USWWP-oxy. Figure 6 illustrates the abundance of each element in the various ash streams. The colored lines connecting the data points are for easier tracking only.

The appropriate explanation of the elemental distribution trend in each fly ash stream and the bottom deposition requires a closer inspection to the melting points as well as the condensation points of the commonly identified compounds of the ash minerals. It is possible, that the mineral form with the highest condensation temperature is expected to slag and stick to other ash solid particles (metal oxides) or stick to the furnace walls by condensation, earlier
Table 5.

Elemental analysis (wt.\%) of CLA, FTA, BOA, and BCD.

\begin{tabular}{|c|c|c|c|c|c|c|}
\hline Combustion case & Element & $\begin{array}{c}\text { CLA } \\
\text { (wt.\%) }\end{array}$ & $\begin{array}{c}\text { FTA } \\
\text { (wt.\%) }\end{array}$ & $\begin{array}{c}\text { BOA } \\
\text { (wt.\%) }\end{array}$ & $\begin{array}{c}\text { BCD } \\
(\text { wt. \%) }\end{array}$ & Av. STDEV \\
\hline \multirow{13}{*}{ USWWP-Air } & $\mathrm{Si}$ & 4.75 & 2.82 & 5.80 & 7.22 & \pm 0.43 \\
\hline & $\mathrm{Al}$ & 1.66 & 2.32 & 0.91 & 3.38 & \pm 0.13 \\
\hline & $\mathrm{Ca}$ & 40.22 & 16.25 & 35.58 & 25.47 & \pm 1.60 \\
\hline & $\mathrm{Mg}$ & 4.58 & 1.43 & 3.22 & 6.88 & \pm 0.21 \\
\hline & $\mathrm{Ba}$ & 0.27 & 0.32 & 0.22 & 0.30 & \pm 0.02 \\
\hline & $\mathrm{K}$ & 2.68 & 21.69 & 3.20 & 14.54 & \pm 0.52 \\
\hline & $\mathrm{Na}$ & 0.63 & 2.11 & 0.58 & 1.69 & \pm 0.03 \\
\hline & $\mathrm{Fe}$ & 2.57 & 4.42 & 1.80 & 3.18 & \pm 0.37 \\
\hline & $\mathrm{Mn}$ & 3.89 & 1.88 & 3.36 & 2.73 & \pm 0.15 \\
\hline & $\mathrm{Ti}$ & 0.17 & 0.15 & 0.17 & 0.39 & \pm 0.01 \\
\hline & $\mathrm{P}$ & 2.04 & 1.51 & 1.66 & 2.46 & \pm 0.13 \\
\hline & $S$ & 0.45 & 6.20 & 0.90 & 1.32 & \pm 0.19 \\
\hline & $\mathrm{Cl}$ & 0.10 & 1.70 & 0.13 & 0.00 & \pm 0.05 \\
\hline \multirow{13}{*}{ USWWP - Oxy } & $\mathrm{Si}$ & 6.76 & 3.92 & 9.03 & 5.78 & \pm 0.37 \\
\hline & $\mathrm{Al}$ & 1.95 & 3.09 & 1.69 & 3.07 & \pm 0.20 \\
\hline & $\mathrm{Ca}$ & 34.87 & 17.11 & 37.36 & 28.61 & \pm 1.50 \\
\hline & $\mathrm{Mg}$ & 3.71 & 1.56 & 4.21 & 8.05 & \pm 0.23 \\
\hline & $\mathrm{Ba}$ & 0.27 & 0.31 & 0.32 & 0.30 & \pm 0.01 \\
\hline & $\mathrm{K}$ & 4.65 & 21.96 & 3.52 & 13.20 & \pm 1.09 \\
\hline & $\mathrm{Na}$ & 0.83 & 2.00 & 0.65 & 1.62 & \pm 0.18 \\
\hline & $\mathrm{Fe}$ & 3.17 & 4.57 & 2.85 & 2.58 & \pm 0.25 \\
\hline & $\mathrm{Mn}$ & 3.19 & 1.47 & 3.66 & 3.36 & \pm 0.14 \\
\hline & $\mathrm{Ti}$ & 0.25 & 0.21 & 0.28 & 0.35 & \pm 0.01 \\
\hline & $\mathrm{P}$ & 1.78 & 1.57 & 1.98 & 2.72 & \pm 0.12 \\
\hline & $\mathrm{S}$ & 1.13 & 7.20 & 0.75 & 0.08 & \pm 0.41 \\
\hline & $\mathrm{Cl}$ & 0.26 & 0.91 & 0.18 & 0.03 & \pm 0.02 \\
\hline
\end{tabular}

than other forms of that mineral. Not all these particles will reach the wall, therefore the remaining particles will either freeze with the temperature decrease and remain in the fly ash, or deposit on the first surface they impact upon, such as the furnace bottom and FG pipe (in this study case). The deposition site depends on the melting point. The lower melting point of a compound extends the deposition to further surfaces of the heat exchange, whereas the high melting point ends the deposition occurrence at an earlier stage. On the other hand, the low condensation-temperature compounds can remain in the vapor phase to be conveyed with the flue gases to further cooling stages, then condense and deposit on the heat exchanger tube surfaces. Taking into consideration the effect of the chemical equilibrium and stability of each compound, the deposition prediction can be closer to the actual occurrence. Hence, a review of all the condensation and melting points of the potential mineral compounds was conducted, bearing in mind that the flue gases in this study case leave the furnace at $790-850^{\circ} \mathrm{C}$.

In the combustion furnace, alkali, sulphur, and chlorine are expected to be released as vapors and react in the gas phase in the presence of oxygen and water vapor to form alkali sulfates and chlorides (Miles et al., 1996). $\mathrm{K}_{2} \mathrm{SO}_{4}$ is expected to be the first slagging precursor as it has the highest condensation temperature $\left(1689^{\circ} \mathrm{C}\right)$. Then, these sticky particles adhere to the furnace walls and trap the metal oxides $\left(\mathrm{CaO}, \mathrm{MgO}, \mathrm{FeO}, \mathrm{Al}_{2} \mathrm{O}_{3}\right)$ to form a thin fused glassy film on the walls (Misra et al., 1993). Downstream of the furnace, the dissociation of $\mathrm{K}_{2} \mathrm{CO}_{3}$ to $\mathrm{K}_{2} \mathrm{O}$ occurs at $900{ }^{\circ} \mathrm{C}$, where $\mathrm{K}_{2} \mathrm{O}$ can mix with silica to form low-melting eutectics with silicates (Baxter et al., 1993), hence may initiate the agglomeration on the furnace bottom 

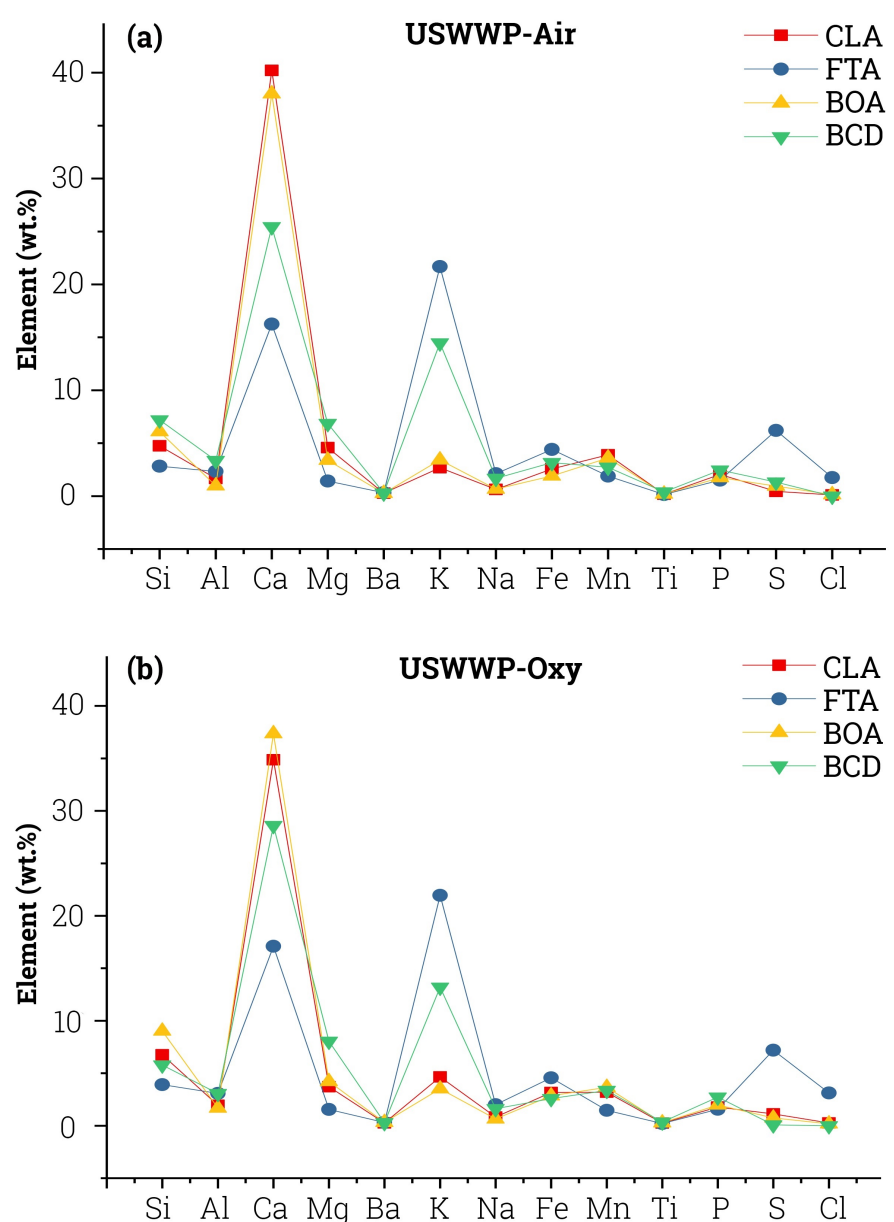

Fig. 6. Elemental analysis of the ash in CLA, FTA, BOA, and BCD, of the investigated combustion cases; (a) USWWP-air and (b) USWWP-oxy.

Table 6.

Elemental oxides composition of the fuel ash, CLA, FTA, BOA and BCD, as wt.\%. and tube surfaces. Potassium silicate is a corrosive, irritant material that can cause severe corrosion to the boiler surfaces. In general, the basic oxides $\left(\mathrm{CaO}, \mathrm{MgO}, \mathrm{K}_{2} \mathrm{O}, \mathrm{Na}_{2} \mathrm{O}, \mathrm{P}_{2} \mathrm{O}_{5}\right)$ can react with the acidic oxides $\left(\mathrm{SiO}_{2}\right.$ $\mathrm{Fe}_{2} \mathrm{O}_{3}, \mathrm{MnO}, \mathrm{Al}_{2} \mathrm{O}_{3}$ ) to form a ceramic-form deposition. $\mathrm{K}_{2} \mathrm{O}$ is the least stable among the potassium compounds, as it decomposes at $300{ }^{\circ} \mathrm{C}$. Therefore, potassium vapors are found in the early stages of the combustion process. Due to the high reactivity of alkali material, they are considered the principal cause of the deposition problems (Öhman et al., 2004; Nutalapati et al., 2007; Shao et al., 2012).

Wood pellets are primarily rich with calcium and potassium. Calcium was pronounced in all the fly ash streams, i.e., CLA, FTA, BOA, as well as bottom deposition BCD. The melting point of $\mathrm{CaO}$ and $\mathrm{CaSO}_{4}$ are $2613{ }^{\circ} \mathrm{C}$ and $1460{ }^{\circ} \mathrm{C}$, respectively, thus they are expected to comprise the fly ash calcium, whereas the calcium in the deposit is expected to agglomerate with silica and alumina to form a complex of aluminosilicates. Most of the fuel ash potassium was collected with the filter ash and the bottom deposition (21.69\% FTA, and $14.54 \%$ BCD). The high abundance of potassium and sulphur in the FTA suggests that the $\mathrm{K}_{2} \mathrm{SO}_{4}$ was the main form of potassium in the fly ash, as it was in the solid phase at the exit of the furnace given its high melting point of $1069^{\circ} \mathrm{C}$, and the particle size was small enough to be conveyed to the candle filter. Previous studies on wood and wood pellets combustion observed potassium sulphate in the upper furnace sections and in the convective passes (Wiinika et al., 2014).

However, the sulphur was not enough to react with all the potassium. Therefore, a large fraction of the potassium deposited in the furnace bottom $\mathrm{BCD}$, and the expected forms were $\mathrm{K}_{2} \mathrm{SiO}_{3}, \mathrm{KCl}, \mathrm{K}_{2} \mathrm{O}$, and $\mathrm{KOH}$, as their melting points are lower than $800{ }^{\circ} \mathrm{C}\left(750,770,740\right.$, and $360{ }^{\circ} \mathrm{C}$, respectively). Considering the chemical stability of the three compounds, $\mathrm{KCl}$ is the most stable and has a high boiling point $\left(1420^{\circ} \mathrm{C}\right)$, and therefore the particles are sticky at the furnace exit temperature and could be found attached to the fly ash particles passing the cyclone to be captured with the aerosols in the filter ash FTA. In support of this explanation was the high chlorine content in the FTA relative to the other fly ash streams. In industrial boilers, $\mathrm{KCl}$ was found in the fouling deposition on the super heater tubes (Jenkins et al., 1998). For the USWWP-oxy, Figure 5-b clearly shows the similarity with the air combustion case in the elemental distribution, except the silicon as it was higher in the bottom ash than in the bottom deposition BCD.

In the absence of chlorine, $\mathrm{K}_{2} \mathrm{O}$ could react with silica to form $\mathrm{K}_{2} \mathrm{SiO}_{3}$ that freezes at about $750{ }^{\circ} \mathrm{C}$, or react with $\mathrm{CO}_{2}$ to form $\mathrm{K}_{2} \mathrm{CO}_{3}$, and then initiated the bottom agglomeration. Therefore, the potassium and silicon were abundant in the BCD. A notable finding from the ash composition analysis was that the total elemental content as metal oxides in the $550{ }^{\circ} \mathrm{C}$ ash did not add up to $100 \%$. Table 6 shows the ash compositions as metal

\begin{tabular}{|c|c|c|c|c|c|c|c|c|c|}
\hline \multirow{2}{*}{ Elemental oxides } & \multirow{2}{*}{ Afuel } & \multicolumn{4}{|c|}{ USWWP - Air } & \multicolumn{4}{|c|}{ USWWP - OXY } \\
\hline & & CLA & FTA & BOA & BCD & CLA & FTA & BOA & BCD \\
\hline $\mathrm{SiO}_{2}$ & 12.55 & 10.17 & 8.38 & 12.41 & 15.45 & 14.45 & 8.38 & 19.31 & 12.37 \\
\hline $\mathrm{Al}_{2} \mathrm{O}_{3}$ & 5.04 & 3.14 & 5.83 & 1.72 & 6.39 & 3.68 & 5.83 & 3.18 & 5.80 \\
\hline $\mathrm{CaO}$ & 40.32 & 56.28 & 23.93 & 49.78 & 35.64 & 48.78 & 23.93 & 52.27 & 40.03 \\
\hline $\mathrm{MgO}$ & 8.91 & 7.60 & 2.58 & 5.34 & 11.41 & 6.15 & 2.58 & 6.98 & 13.35 \\
\hline $\mathrm{BaO}$ & 0.32 & 0.31 & 0.34 & 0.24 & 0.33 & 0.30 & 0.34 & 0.35 & 0.33 \\
\hline $\mathrm{K}_{2} \mathrm{O}$ & 14.14 & 3.23 & 26.45 & 3.85 & 17.52 & 5.60 & 26.45 & 4.23 & 15.90 \\
\hline $\mathrm{Na}_{2} \mathrm{O}$ & 1.89 & 0.84 & 2.70 & 0.79 & 2.27 & 1.11 & 2.70 & 0.88 & 2.19 \\
\hline $\mathrm{Fe}_{2} \mathrm{O}_{3}$ & 4.48 & 3.67 & 6.53 & 2.58 & 4.55 & 4.53 & 6.53 & 4.07 & 3.69 \\
\hline $\mathrm{MnO}_{2}$ & 4.71 & 6.16 & 2.33 & 5.32 & 4.32 & 5.04 & 2.33 & 5.78 & 5.32 \\
\hline $\mathrm{TiO}_{2}$ & 0.48 & 0.29 & 0.35 & 0.29 & 0.65 & 0.41 & 0.35 & 0.47 & 0.59 \\
\hline $\mathrm{P}_{2} \mathrm{O}_{5}$ & 5.02 & 4.68 & 3.59 & 3.80 & 5.64 & 4.07 & 3.59 & 4.54 & 6.24 \\
\hline $\mathrm{SO}_{3}$ & 4.28 & 1.12 & 17.98 & 2.25 & 3.30 & 2.81 & 17.98 & 1.86 & 0.19 \\
\hline Total & 102.16 & 97.49 & 100.98 & 88.39 & 107.48 & 96.94 & 100.98 & 103.93 & 105.99 \\
\hline Undetected & -2.16 & 2.51 & -0.98 & 11.61 & -7.48 & 3.06 & -0.98 & -3.93 & -5.99 \\
\hline
\end{tabular}


oxides. The undetected fractions of the ash could be attributed to the presence of carbon in the form of metal carbonates that decomposes at temperatures above $700{ }^{\circ} \mathrm{C}$ to the metal oxide. It has been shown that the ash content of the biomass is reduced by $30-47 \%$ when the biomass was burned in temperatures higher than $1000^{\circ} \mathrm{C}$ compared with the ash produced at a temperature of $550^{\circ} \mathrm{C}$ (Ragland et al., 1991; Misra et al., 1993). On the other hand, total metal oxides higher than $100 \%$ can be explained by the formation of multi-element silicates and oxides during the deposition process requiring lower amounts of oxygen, that were over predicted by individual oxides.
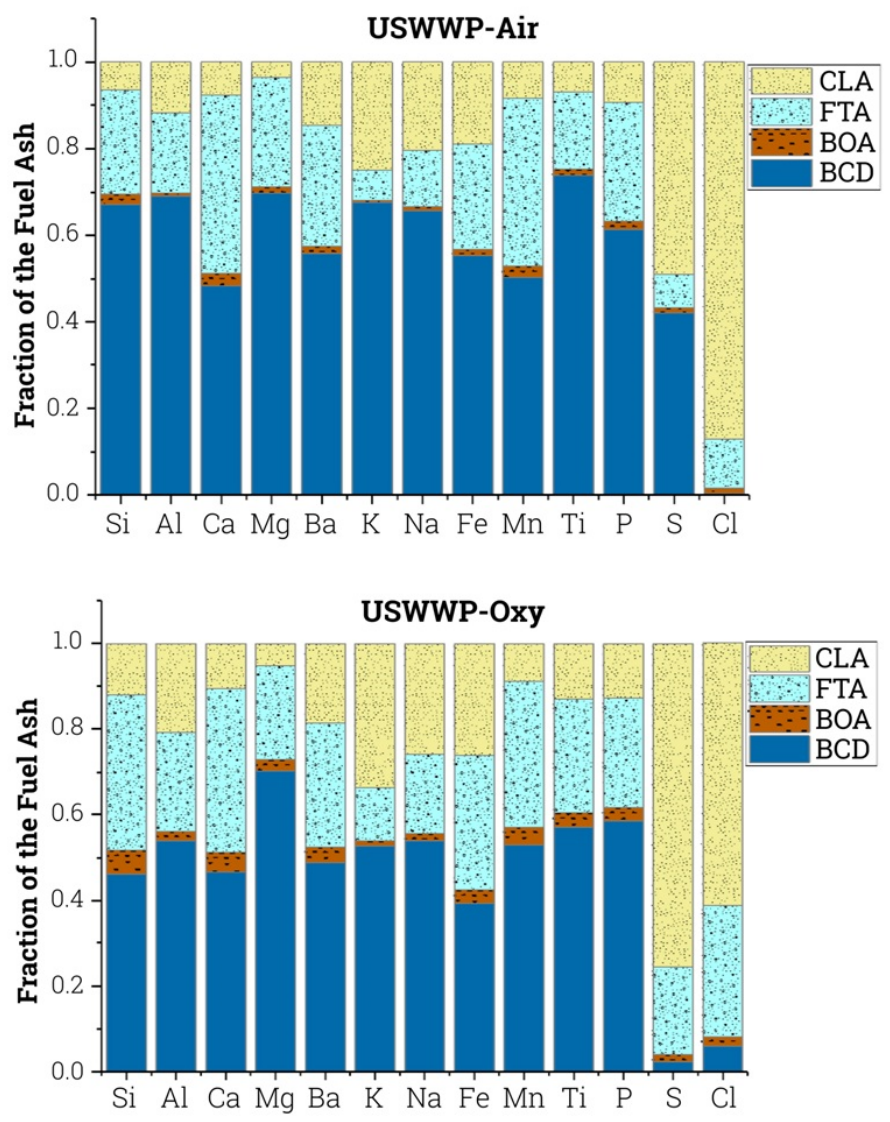

Fig. 7. Relative abundance of ash elements in the sampling zones, i.e., FTA, CLA, BOA, and $\mathrm{BCD}$, normalized by the fuel ash for the USWWP-air and USWWP-oxy cases.

\subsection{Fuel ash partitioning}

The relative abundance of each element in the ash streams to the original fuel ash composition is shown in Figure 7. These values were calculated by normalizing the elemental concentrations in the fly ash streams and the bottom deposit by those in the fuel. The effect of the oxidant environment on the ash behaviour was more recognized herein. As can be seen from Figure 7, the fractional distribution of the ash elements among the four streams was clearly different between the air and oxy-fuel cases, mainly the alkali, chlorine, and sulphur. Higher fractions of alkali and sulphur were in the BCD in the air-fuel case, indicating higher amounts of alkali sulphates and chlorides seen in the furnace bottom deposition. In addition, more metal oxides such as silica, alumina, iron oxide, and titanium oxide were conveyed with the FTA in the oxy-fuel case than those in the air-fuel case.

These correlations suggest that the oxy-fuel combustion inhibited the release of volatile elements to the gas phase in the early stages of the combustion, reducing the alkali slagging, and hence reducing the furnace wall deposition, increasing however, the alkali fouling in later stages of the heat exchange.
Furthermore, the high chlorine fraction in the BCD of the oxy-fuel case suggests higher alkali chlorides were trapped on the furnace walls and the bottom, whereas, the air-fuel released more chlorine with the FTA and CLA indicating higher corrosion problems could be expected on the heat exchanger surfaces.

\subsection{Chemical equilibrium calculations}

The phase equilibrium at the flame zone revealed slag formation in both combustion cases. Figure 8 illustrates the formation of slag and solid phases of the condensed particle forming species during the cooling process of the flue gases. Mass fraction of each non-gas phase formed in each combustion case was normalized to the fuel ash content. Biomass ash started slagging at 0.32 and 0.37 for air and oxy cases, respectively, and gradually dropped to zero at $700-600{ }^{\circ} \mathrm{C}$. Accordingly, a dramatic increase in the solid phase of biomass ash occurred at $900-700{ }^{\circ} \mathrm{C}$ and continued to increase until $200{ }^{\circ} \mathrm{C}$, indicating more deposition problems on the convective passes. The chemical equilibrium in this study resulted into extended slag phase to lower temperatures than the range reported by Xing et al. (2016) due to the difference in the experimental scale.

Interestingly, the air-fuel environment extended slag phase to lower temperatures than the oxy case, that increased the ultimate solid fraction of the ash particles, and this could be translated to lower deposit formation. This result supports the experimental finding of the effect of oxy-fuel on ash deposit formation. It is noticeable, however, that the chemical equilibrium model has over predicted the solid phase of wood pellets for both cases in the lower temperature range $\left(600-200^{\circ} \mathrm{C}\right)$ that the combined solid and slag phases exceeded the original ash content in the fuel.

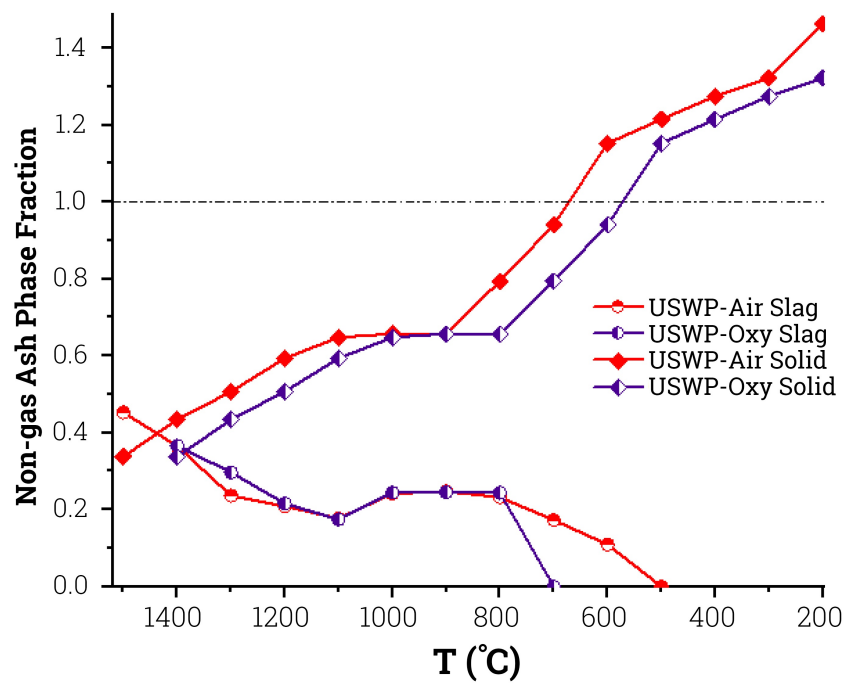

Fig. 8. Non-gas phase development during condensation of flue gases for the USWWP-Air and the USWWP-Oxy combustion cases predicted by the FactSage chemical equilibrium.

\subsubsection{Prediction of alkali species formation}

As the alkali compounds are the main reason for slagging and corrosion in the combustion process, the predicted alkali forms by the FactSage are discussed in detail in this section. The chemical equilibrium results of the alkali species that were formed during condensation process are plotted with the temperature as shown in Figure 9. At the radiation zone, the predicted alkali species were mainly $\mathrm{KOH}$ vapour, and minimal amounts of $\mathrm{K}_{2} \mathrm{SO}_{4}$ and $\mathrm{K}_{2} \mathrm{O}$ slags. Then at $1100{ }^{\circ} \mathrm{C}$, more of the hydroxides were condensed to form sulphate and oxide slags. At $800-700{ }^{\circ} \mathrm{C}$, all the hydroxides and slags disappeared, and solid species were formed such as $\mathrm{K}_{2} \mathrm{SO}_{4}, \mathrm{KCl}$, and $\mathrm{K}_{2} \mathrm{Ca}_{2}\left(\mathrm{CO}_{3}\right)_{2}$. 

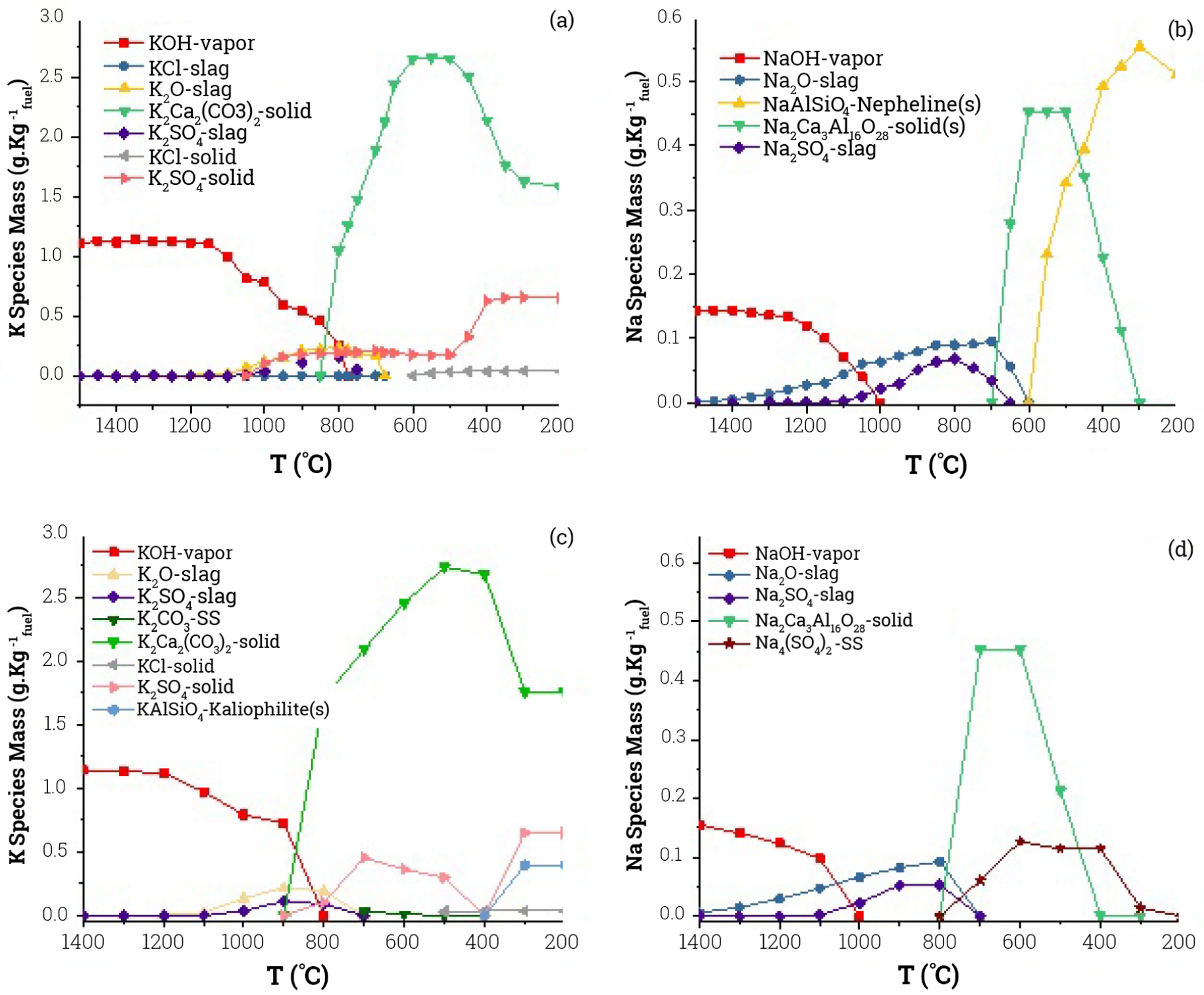

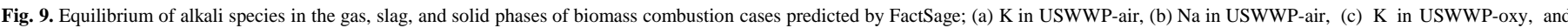
(d) $\mathrm{Na}$ in USWWP-oxy.

A similar trend was found for potassium in the USWWP-oxy case (Fig. 9c) except higher solid sulphate was formed at temperatures lower than $800^{\circ} \mathrm{C}$, and this explains the higher sulphur content that was found experimentally in the filter ash of the oxy-fuel case. In addition, oxy-fuel conditions promoted forming potassium silicates $\mathrm{KAlSiO}_{4}$ and $\mathrm{K}_{2} \mathrm{CO}_{3}$ suggesting more potassium could be found in the ash deposition.

The sodium had the same behaviour in terms of forming hydroxide vapour and $\mathrm{Na}_{2} \mathrm{SO}_{4}$ slag at higher temperatures and solid $\mathrm{Na}_{2} \mathrm{SO}_{4}$ at the flue gas exit temperatures, as illustrated in Figure 9d, also forming complex oxide and silicate with calcium and aluminium. The prediction of higher alkali compounds in the oxy-fuel slag phase explains the lower alkali content found in the experimental fly ash than that of the air-fuel case. Moreover, the higher sodium sulphate at the convective passes temperatures suggests more fouling problems than the ones in the air-fuel case.

\section{Conclusions}

The results of this study showed that wood pellets had a low tendency for radiation zone slagging but had high fouling tendency in the convective passes. It is possible that oxy-fuel combustion inhibited the release of volatile elements to the gas phase in the initial stages of the combustion, thus reducing the alkali sulphates slagging, increasing however, the alkali sulphate fouling tendencies on the convective passes. On the other hand, higher alkali chlorides were expected to be found on the furnace walls and bottom, whereas, less chlorine was released to the fly ash, thus indicating lower propensity of high-temperature corrosion problems on the heat exchanger surfaces. The chemical equilibrium modelling using FactSage showed reasonable predictions of the ash behaviour for wood pellets in terms of alkali behaviour and explained to some extent the influence of oxy environment on the ash deposition formation. 
Further research could usefully explore the actual deposition occurrence of the wood pellets, in different combustion environments. In addition, investigating more biomass fuels with oxy-fuel combustion can generate a wide database that assists to conclude general behaviour of biomass and improved validation of the ash deposition modelling.

\section{Acknowledgement}

The authors acknowledge that the UKCCSRC PACT Facilities, funded by the Department for Business, Energy, and Industrial Strategy and the Engineering and Physical Sciences Research Council, have been used for experimental work reported in this publication. The authors thank Dr. Zandi and Dr. Nik Reeves for their support to perform the laboratory analysis, and Dr. Janos Szuhanszki for his help in running the pilot scale combustion experiments.

\section{References}

[1] Bale, C.B., Belslie, E., Chartrand, P., 2015. FactSage thermochemical software and database. Thermfact Ltd. and GTT-Technologies, Montreal, Aachen-Canada.

[2] Baxter, L.L., Miles, T.R., Miles Jr, T.R., Jenkins, B.M., Milne, T., Dayton, D., Bryers, R.W., Oden, L.L., 1998. The behavior of inorganic material in biomass-fired power boilers: field and laboratory experiences. Fuel Process. Technol. 54(1-3), 47-78.

[3] Baxter, L.L., 1993. Ash deposition during biomass and coal combustion: a mechanistic approach. Biomass Bioenergy. 4(2), 85-102.

[4] Fryda, L., Sobrino, C., Cieplik, M., 2014. Comparative study of ash deposition under air and oxyfuel combustion of coal/biomass blends / paper number 810315. Proceeding of the European Combustion Meeting.

[5] Gruber, T., Scharler, R., Obernberger, I., 2015. Application of an empirical model in CFD simulations to predict the local high temperature corrosion potential in biomass fired boilers. Biomass Bioenergy. 79, 145-154.

[6] Houshfar, E., Wang, L., Vähä-Savo, N., Brink, A., Løvås, T., 2014. Characterisation of $\mathrm{CO} / \mathrm{NO} / \mathrm{SO}_{2}$ emission and ash-forming elements from the combustion and pyrolysis process. Clean Technol. Environ. Policy. 16(7), 1339-1351.

[7] Jenkins, B., Baxter, L.L., Miles Jr., T.R., Miles, T.R., 1998. Combustion properties of biomass. Fuel Process. Technol. 54(1-3), 17-46.

[8] Miles, T.R., Miles Jr., T.R., Baxter, L.L., Bryers, R.W., Jenkins, B.M., Oden, L.L., 1996. Boiler deposits from firing biomass fuels. Biomass Bioenergy. 10(2-3), 125-138.
[9] Misra, M.K., Ragland, K.W., Baker, A.J., 1993. Wood ash composition as a function of furnace temperature. Biomass Bioenergy. 4(2), 103-116.

[10] Nutalapati, D., Gupta, R., Moghtaderi, B., Wall, T.F., 2007. Assessing slagging and fouling during biomass combustion: thermodynamic approach allowing for alkali/ash reactions. Fuel Process. Technol. 88 (11-12), 1044-1052.

[11] Öhman, M., Nordin, A., Hedman, H., Jirjis, R., 2004. Reasons for slagging during stemwood pellet combustion and some measures for prevention. Biomass Bioenergy. 27(6), 597-605.

[12] Pronobis, M., 2005. Evaluation of the influence of biomass cocombustion on boiler furnace slagging by means of fusibility correlations. Biomass Bioenergy. 28(4), 375-383.

[13] Ragland, K.W., Aerts, D.J., Baker, A.J., 1991. Properties of wood for combustion analysis. Bioresour. Technol. 37(2), 161-168.

[14] Ragland, K.W., Misra, M.K., Aerts, D.J., Palmer, C.A., 1995. Ash deposition in a wood-fired gas turbine. J. Eng. Gas Turbines Power. 117(3), 509-512.

[15] Shao, Y., Wang, J., Preto, F., Zhu, J., Xu, C., 2012. Ash deposition in biomass combustion or co-firing for power/heat generation. Energies. 5(12), 5171-5189.

[16] Shao, Y., Xu, C., Zhu, J., Preto, F., Wang, J., Tourigny, G., Badour, C., Li, H., 2010. Ash deposition during co-firing biomass and coa in a fluidized-bed combustor. Energy Fuels. 24(9), 4681-4688.

[17] Sommersacher, P., Brunner, T., Obernberger, I., 2012. Fuel indexes: a novel method for the evaluation of relevant combustion properties of new biomass fuels. Energy Fuels. 26(1), 380-390.

[18] Vamvuka, D., Zografos, D., Alevizos, G., 2008. Control methods for mitigating biomass ash-related problems in fluidized beds. Bioresour. Technol. 99(9), 3534-3544.

[19] Wei, X., Schnell, U., Hein, K.R., 2005. Behaviour of gaseous chlorine and alkali metals during biomass thermal utilisation. Fuel. 84(7-8), 841-848.

[20] Wiinikka, H., Gebart, R., Boman, C., Boström, D., Öhman, M. 2007. Influence of fuel ash composition on high temperature aeroso formation in fixed bed combustion of woody biomass pellets. Fuel. 86(1-2), 181-193.

[21] Wiinikka, H., Weiland, F., Pettersson, E., Öhrman, O., Carlsson, P. Stjernberg, J., 2014. Characterisation of submicron particles produced during oxygen blown entrained flow gasification of biomass. Combust. Flame. 161(7), 1923-1934.

[22] Xing, P., Darvell, L.I., Jones, J.M., Ma, L., Pourkashanian, M. Williams, A., 2016. Experimental and theoretical methods for evaluating ash properties of pine and El Cerrejon coal used in cofiring. Fuel, 183, 39-54. 